\title{
KAJAN EKONOMI PENUNDAAN BUKA SADAP SEBAGAI SOLUSI UNTUK MENGHADAPI HARGA KARET RENDAH
}

Economic Analysis of Delaying of Rubber Opening as a Solution to Deal with the Low Rubber Price

\author{
Dwi Shinta Agustina, Eva Herlinawati, dan Iman Satra Nugraha \\ Balai Penelitian Sembawa, Jln. Raya Palembang-Pangkalan Balai Km.29, \\ PO BOX 1127, Palembang 30001 \\ Email : dwishinta_sbw@yahoo.com
}

Diterima 11 April 2016 / Direvisi 14 Juni 2017 / Disetujui 15 Juni 2017

\begin{abstract}
Abstrak
Agribisnis karet saat ini sedang mengalami kondisi yang kurang menguntungkan. Hal ini disebabkan oleh menurunnya harga karet beberapa tahun terakhir serta meningkatnya biaya produksi terutama biaya penyadapan. Salah satu upaya yang dapat dilakukan dan dapat menjadi suatu pemikiran adalah dengan melakukan penundaan buka sadap tanaman karet. Tulisan ini mengkaji penundaan buka sadap tanaman karet dengan dua pendekatan yaitu: penundaan buka sadap tanaman karet dengan merubah kriteria matang sadap pohon dari $45 \mathrm{~cm}$ menjadi $50 \mathrm{~cm}$; dan penundaan buka sadap tanaman karet dengan merubah kriteria persentase matang sadap kebun. Analisis menggunakan data percobaan mengenai waktu pembukaan sadap dari beberapa penelitian terdahulu. Hasil kajian menunjukkan bahwa penundaan buka sadap dengan merubah lilit batang dari $45 \mathrm{~cm}$ menjadi 50 $\mathrm{cm}$ dapat meningkatkan produktivitas per penyadap. Penundaan buka sadap hingga lilit batang mencapai $50 \mathrm{~cm}$ akan ekonomis dengan pemilihan klon yang memiliki produktivitas awal yang tinggi. Penundaan buka sadap dari lilit batang $45 \mathrm{~cm}$ menjadi 50 cm memerlukan waktu 6-12 bulan tergantung kerapatan tanaman dan jenis klon. Kriteria matang sadap kebun yang berbeda sesuai jenis klon dan perubahan harga masih menguntungkan secara ekonomis. Perlu kajian yang lebih mendalam mengenai
\end{abstract}

penundaan buka sadap terhadap klon-klon anjuran baru.

Kata kunci: karet, buka sadap, penundaan

\section{Abstract}

Currently, agribusiness of rubber is experiencing unfavorable condition. This is due to the declining of rubber price in the last few years as well as increasing of cost of production especially the cost of tapping. An effort that could be done was by delaying the opening of rubber. This paper examines the delay in opening of rubber with two approaches, i.e. delaying of rubber opening by changing the criteria of tree maturity for tapping from $45 \mathrm{~cm}$ to $50 \mathrm{~cm}$; and delaying of rubber opening by changing the criteria for the percentage of mature tree. Analysis was conducted using the data of Lukman (1979;1980), Samuel et al. (2012), Hendratno and Amypalupy (2008), and Nugraha et al. (2015). The results showed that the delay of opening by changing the girth of $45 \mathrm{~cm}$ to $50 \mathrm{~cm}$ could increase productivity per tapper. Delaying of opening until reaching the girth of 50 $\mathrm{cm}$ will be economical with the selection of clones that have high initial productivity. To delay opening from the girth of $45 \mathrm{~cm}$ to $50 \mathrm{~cm}$ took $6-12$ months depending on the density of the plants and clones. The different criteria of field tapping maturity suitable of clone type and price changes are still economically viable. Need more extensive study on the delaying of open tapping to new recommend clone.

Keywords: rubber, opening, delaying 


\section{Pendahuluan}

Karet alam merupakan salah satu komoditas unggulan karena merupakan sumber devisa negara, sumber mata pencaharian penduduk, dan pelestari lingkungan. Pada tahun 2013, volume ekspor karet alam Indonesia mencapai 2,7 juta ton dengan nilai ekspor mencapai US\$ 6,9 juta (BPS, 2013). Selain itu, karet juga menjadi sumber mata pencaharian bagi lebih dari 2 juta keluarga petani (Ditjenbun, 2014).
Agribisnis karet saat ini sedang mengalami kondisi yang kurang menguntungkan. Hal ini disebabkan oleh menurunnya harga karet beberapa tahun terakhir serta meningkatnya biaya produksi terutama biaya penyadapan. Harga karet mencapai puncak tertinggi pada tahun 2011, namun sejak tahun 2012-2015 harga karet terus mengalami penurunan hingga mencapai harga US\$ 1,36 per $\mathrm{kg}$ (SICOM, 2015). Fluktuasi harga karet sejak tahun 1998 sampai 2015 ditampilkan pada Gambar 1 .

\section{$\longrightarrow$-Harga TSR20 (cent US\$/kg)}

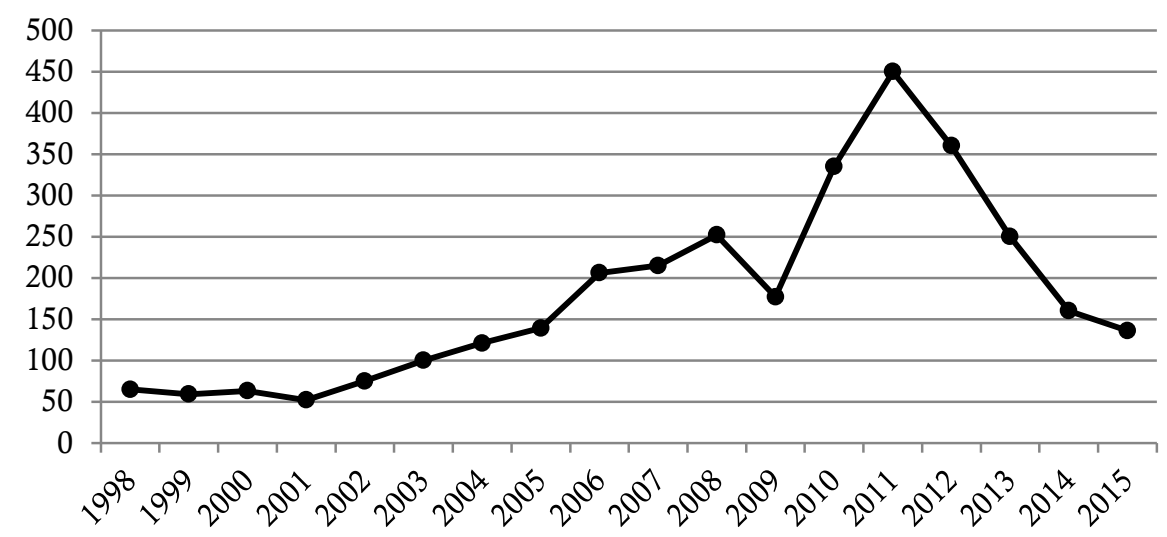

Gambar 1. Fluktuasi harga Technical Specified Rubber (TSR) 20 (SICOM, 1998-2015)

Selain faktor turunnya harga karet, faktor biaya produksi yang terus mengalami peningkatan membuat agribisnis karet menjadi semakin terpuruk. Biaya penyadapan merupakan komponen biaya terbesar dalam usahatani karet $(40 \%-60 \%$ dari total biaya produksi) (Karyudi dan Junaidi, 2009; Sivakumaran, 2013). Peningkatan biaya penyadapan terutama disebabkan oleh kenaikan upah tenaga penyadap. Jika pada tahun 2011 upah penyadap di salah satu perkebunan di Sumatera Selatan adalah $\mathrm{Rp}$ $50.000,-/$ hari, maka pada tahun 2015 upah tersebut naik menjadi $\mathrm{Rp} 77.000,-/$ hari atau meningkat sebesar 54\%. Hal ini sangat memberatkan bagi pelaku bisnis perkebunan karet.Biaya lain yang turut mempengaruhi biaya produksi adalah peningkatan harga sarana produksi pertanian (pupuk, pestisida, obat-obatan) dan alat/mesin pertanian sebagai akibat adanya inflasi dan penerapan kebijakan pengurangan/penghapusan subsidi oleh pemerintah (Hendratno dan Amypalupy, 2008).

Menurut data dari ITRC (2015), diketahui bahwa biaya produksi TSR20 pada tahun 2015 di tiga negara produsen karet dunia (Thailand, Indonesia, dan Malaysia) saat ini masing-masing adalah US\$ cent $188,20 / \mathrm{kg}$; US\$ cent $141,92 / \mathrm{kg}$; dan US\$ cent $110,31 / \mathrm{kg}$. Berdasarkan data tersebut dapat dilihat bahwa dengan kondisi harga karet sebesar US\$ cent $136 / \mathrm{kg}$ tidak dapat menutupi biaya produksi tersebut. Oleh karena itu perlu upaya efisiensi usahatani karet untuk menekan harga pokok sehingga perusahaan masih memperoleh keuntungan. 
Salah satu upaya yang dapat dilakukan dan dapat menjadi suatu kajian adalah dengan melakukan penundaan buka sadap tanaman karet. Secara konvensional, suatu kebun karet dianggap mencapai matang sadap jika $\geq 60 \%$ dari jumlah pohon karet per ha telah mempunyai lilit batang $\geq 45 \mathrm{~cm}$ (diukur pada ketinggian $100 \mathrm{~cm}$ di atas pertautan okulasi) (Kuswanhadi dan Herlinawati, 2012). Namun, dengan kondisi perekonomian yang dinamis terutama pada kondisi harga yang kurang baik, perlu dikaji manfaat/kerugiannya jika perusahaan melakukan penundaan buka sadap tanaman karet.

Tulisan ini mengkaji penundaan buka sadap tanaman karet dengan dua pendekatan yaitu:

1. penundaan buka sadap tanaman karet dengan merubah kriteria matang sadap pohon dari $45 \mathrm{~cm}$ menjadi $50 \mathrm{~cm}$

2. penundaan buka sadap tanaman karet dengan merubah kriteria persentase matang sadap kebun

\section{Kajian Penundaan Buka Sadap pada Berbagai Kondisi}

Kajian penundaan buka sadap pada tanaman karet dengan merubah kriteria matang sadap pohon dari $45 \mathrm{~cm}$ menjadi 50 cm telah dilakukan oleh Lukman (1979; 1980) pada klon GT 1 dengan kerapatan tanaman adalah 416 pohon/ ha dengan sistem sadap $\mathrm{S} / 2$ d2 (147 hari sadap per tahun) dan $\mathrm{S} / 2 \mathrm{~d} 3$ (85 hari sadap per tahun). Studi penundaan buka sadap dilakukan di Kebun Sarang Ginting, PTPN IV Gunung Pamela, Sumatera Utara (sekarang PTPN III) dengan jenis tanah Podsolik Merah Kuning. Tujuan penelitian tersebut adalah untuk memberikan pertumbuhan yang lebih baik bagi tanaman dan sekaligus lebih tahan terhadap angin serta memberikan sifat sekunder yang lebih baik. Hasil studi menunjukkan bahwa produksi karet kering $(\mathrm{g} / \mathrm{p} / \mathrm{s})$ dan produktivitas per penyadap pada lilit batang $50 \mathrm{~cm}$ lebih tinggi dibandingkan pada lilit batang $45 \mathrm{~cm}$. Namun untuk mencapai lilit batang $50 \mathrm{~cm}$, membutuhkan waktu 8 bulan sehingga ada kehilangan produksi kumulatif $(\mathrm{kg} / \mathrm{ha} / \mathrm{tahun})$ selama 8 bulan sebesar $52 \%$.

Selain studi yang dilakukan oleh Lukman (1979; 1980), kajian penundaan buka sadap juga telah dilakukan oleh Samuel, et. al. (2012). Percobaan dilakukan di daerah tenggara Pantai Gading dengan curah hujan $1600 \mathrm{~mm} /$ tahunpadatigajenisklonyaituklon GT 1 (moderate clone), PB 235 (quick starter clone), dan PB 217 (slow starter clone). Kerapatan tanaman sebesar 510 pohon/ ha dengan sistem sadapS $/ 2 \mathrm{~d} 46 \mathrm{~d} / 7$ dan $\mathrm{S} / 2 \mathrm{~d} 4$ $6 \mathrm{~d} / 7$ ET 2,5\% Pa1(1)2/y (78 hari sadap per tahun). Hasil percobaan tersebut menunjukkan hal yang sama dengan hasil studi Lukman $(1979 ; 1980)$ yaitu produksi $\mathrm{g} / \mathrm{p} / \mathrm{s}$ yang dihasilkan oleh tanaman pada lilit batang $50 \mathrm{~cm}$ lebih tinggi dibandingkan tanaman yang dibuka sadap pada lilit batang $45 \mathrm{~cm}$. Disamping itu terjadi peningkatan produktivitas penyadap pada klon GT 1, PB 235, dan PB 217 akibat penundaan buka sadap masing-masing adalah $6,9 \% ; 20,7 \%$; dan $12,2 \%$. Sedangkan jangka waktu yang dibutuhkan tanaman untuk mencapai lilit batang $50 \mathrm{~cm}$ bervariasi tergantung jenis klon. Pada klon GT 1 dan PB 235, penambahan lilit batang dari $45 \mathrm{~cm}$ menjadi $50 \mathrm{~cm}$ dapat dicapai dalam waktu satu tahun. Sementara itu, pada klon PB 217 penambahan lilit batang dari $50 \mathrm{~cm}$ menjadi $55 \mathrm{~cm}$ dapat dicapai dalam waktu enam bulan.

Selanjutnya, Hendratno dan Amypalupy (2008) melakukan suatu studi penentuan formula buka sadap pada kondisi harga karet US\$2,4 per $\mathrm{kg}$ dan biaya produksi yang terus meningkat. Penentuan formula buka sadap dilakukan pada klon PB 260 (quick starter clone), PR 261 (moderate clone), dan RRIC 100 (slow starter clone) dengan sistem sadap S/2 d3. Hasil studi Hendratno dan Amypalupy (2008) menunjukkan bahwa untuk mencapai titik impas maka: 
a. Kebun karet dengan klon quick starter (PB 260) dapat mulai dibuka sadap jika jumlah pohon yang matang sadap mencapai 92 pohon (17\%)

b. Kebun karet dengan klon moderate (PR 261) dapat mulai dibuka sadap jika jumlah pohon yang matang sadap mencapai 115 pohon $(28 \%)$

c. Kebun karet dengan klon slow starter (RRIC 100) dapat mulai dibuka sadap jika jumlah pohon yang matang sadap mencapai 217 pohon (39\%)

Sementara itu, Nugraha et al. (2015) juga melakukan kajian yang sama untuk menentukan formula buka sadap dengan sistem sadap $\mathrm{S} / 2 \mathrm{~d} 3$ pada kondisi harga karet US\$ 1,64 per kg dan biaya produksi yang cenderung naik. Hasil kajian menunjukkan bahwa untuk mencapai titik impas maka:

a. Kebun karet dengan klon quick starter (PB 260) dapat mulai dibuka sadap jika jumlah pohon yang matang sadap mencapai 210 pohon (38\%)

b. Kebun karet dengan klon moderate (PR 261) dapat mulai dibuka sadap jika jumlah pohon yang matang sadap mencapai 354 pohon $(68 \%)$ c. Kebun karet dengan klon slow starter (RRIC 100) dapat mulai dibuka sadap jika jumlah pohon yang matang sadap mencapai 495 pohon (89\%).

\section{Kajian Penundaan Buka Sadap dengan Merubah Kriteria Matang Sadap Pohon}

Penundaan buka sadap dapat menjadi salah satu alternatif dalam menyikapi harga karet yang rendah saat ini. Dari segi produktivitas, penundaan buka sadap dengan aplikasi klon unggul yang memiliki produktivitas awal yang tinggi menunjukkan peningkatan produksi yang signifikan. Hal ini terlihat dari hasil percobaan Samuel et al.(2012) yang ditampilkan pada Gambar 2 . Penundaan buka sadap pada klon quick starter (PB 235) (17,1\%) lebih meningkatkan produksi dibandingkan dengan menggunakan klon dengan metabolisme medium (GT1) $(6,5 \%)$. Oleh sebab itu pemilihan klon yang tepat pada penundaan sadap sangat perlu dilakukan. Disamping itu berdasarkan hasil penelitian yang telah dilakukan oleh Obouayeba et al. (2002) menyatakan bahwa penundaan buka sadap hingga $50 \mathrm{~cm}$ lebih sedikit menurunkan laju perkembangan lilit batang per tahun yaitu sebesar 50\% dibandingkan jika dilakukan penyadapan kurang dari $50 \mathrm{~cm}$.

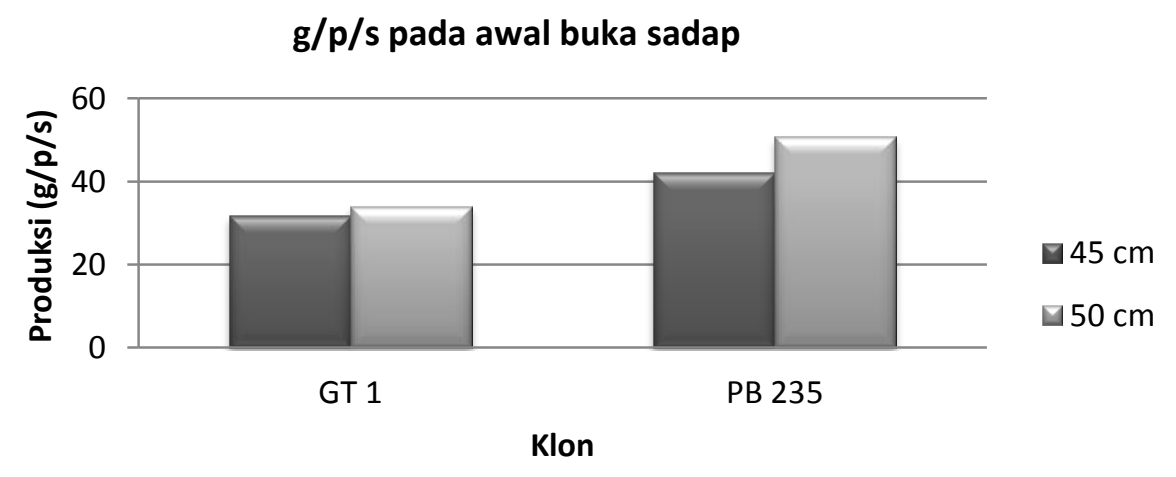

Gambar 2. Produksi (g/p/s) pada awal buka sadap dengan penundaan buka sadap dari lilit batang $45 \mathrm{~cm}$ menjadi $50 \mathrm{~cm}$ pada klon GT 1 dan PB 235 
Namun, secara ekonomis perlu dilihat apakah selisih produksi yang diterima dapat menutupi biaya pemeliharaan selama masa menunggu buka sadap. Berikut ditampilkan hasil analisa ekonomi penundaan buka sadap dari beberapa jenis klon. Adapun asumsi yang digunakan dalam perhitungan ini berdasarkan hasil penelitian Samuel (2012) adalah sebagai berikut:

1. Hari sadap per tahun : 78 hari sadap

2. Kerapatan tanaman/ha : 510 pohon/ha

3. Harga karet adalah $88 \%$ dari harga FOB TSR 20. Harga rata-rata TSR20 pada tahun 2015 adalah US\$1.38 dengan nilai tukar Rp 13.400 sehingga harga karet diasumsikan $\mathrm{Rp} 16.273$,- per $\mathrm{kg}$ karet kering.

4. Harga-harga dan biaya sarana produksi seperti biaya tenaga kerja, alat dan bahan untuk pemupukan, pengendalian gulma hama dan penyakit karet, penyadapan dan pengolahan hasil karet merupakan harga yang berlaku di Balai Penelitian Sembawa

5. Biaya pemeliharaan per tahun : Rp 5.874.195

Tabel 1. Analisis ekonomi pada awal buka sadap dengan penundaan sadap dari lilit batang $45 \mathrm{~cm}$ menjadi $50 \mathrm{~cm}$

\begin{tabular}{lcccccc}
\hline Klon & $\begin{array}{c}\text { Buka } \\
\text { sadap }\end{array}$ & $\mathrm{Kg} / \mathrm{ha} / \mathrm{th}$ & $\begin{array}{c}\text { Biaya } \\
(\mathrm{Rp} / \mathrm{ha} / \mathrm{th})\end{array}$ & $\begin{array}{c}\text { Penerimaan } \\
(\mathrm{Rp} / \mathrm{ha} / \mathrm{th})\end{array}$ & $\begin{array}{c}\text { Pendapatan } \\
(\mathrm{Rp} / \mathrm{h} / \mathrm{th})\end{array}$ & $\begin{array}{c}\text { Selisih } \\
\text { pendapatan }\end{array}$ \\
\cline { 2 - 7 } GT 1 & $\begin{array}{c}57 \text { bulan } \\
(45 \mathrm{~cm})\end{array}$ & 1261 & 15.266 .055 & 20.520 .626 & 5.254 .571 & 1.424 .144 \\
& $\begin{array}{c}69 \mathrm{bulan} \\
(50 \mathrm{~cm})\end{array}$ & 1349 & 15.266 .055 & 21.944 .770 & 6.678 .716 & \\
PB & $\begin{array}{c}63 \mathrm{bulan} \\
(45 \mathrm{~cm})\end{array}$ & 1675 & 15.266 .055 & 27.252 .944 & 11.986 .890 & 5.631 .844 \\
235 & $\begin{array}{l}75 \mathrm{bulan} \\
(50 \mathrm{~cm})\end{array}$ & 2021 & 15.266 .055 & 32.884 .788 & $17,618,734$ & \\
\hline
\end{tabular}

Keterangan: data diolahdari Samuel et al. (2012)

Hasil analisis ekonomi penundaan buka sadap yang ditampilkan pada Tabel 1 menunjukkan bahwa pada klon GT 1, penundaan buka sadap memberikan selisih pendapatan sebesar Rp 1,4 juta. Jika diasumsikan biaya pemeliharaan per tahun adalah $\mathrm{Rp} \mathrm{5,8} \mathrm{juta;} \mathrm{maka} \mathrm{selisih} \mathrm{pendapatan}$ ini belum dapat menutupi biaya pemeliharaan selama menunggu buka sadap (1 tahun). Hasil ini juga sama dengan hasil yang diperoleh dari percobaan Lukman (1980) pada klon GT 1 yang menunjukkan bahwa selisih pendapatan yang diperoleh dengan menunda buka sadap dari lilit batang $45 \mathrm{~cm}$ menjadi $50 \mathrm{~cm}$ belum dapat menutupi biaya pemeliharaan selama masa menunggu buka sadap.
Selanjutnya, dari Tabel 1 juga diketahui bahwa untuk klon PB235, dengan menunda buka sadap sampai mencapai lilit batang 50 $\mathrm{cm}$, diperoleh selisih pendapatan sebesar $\mathrm{Rp}$ 5,6 juta. Dengan asumsi biaya pemeliharaan sebesar $\mathrm{Rp}$ 5,8 juta per tahun, maka selisih pendapatan tersebut juga belum dapat menutupi biaya pemeliharaan selama menunggu buka sadap (1 tahun). Namun, dengan melakukan beberapa pengurangan biaya pemeliharaan (misalnya dengan mengurangi dosis pupuk, frekuensi pengendalian gulma dan penyakit) maka biaya pemeliharaan selama menunggu buka sadap diharapkan dapat ditutupi dari selisih pendapatan tersebut. 


\section{Kajian Penundaan Buka Sadap dengan Merubah Kriteria Matang Sadap Kebun}

Kajian ekonomi penundaan buka sadap dengan merubah kriteria matang sadap kebun dilakukan dengan menggunakan data hasil perhitungan Hendratno dan Amypalupy (2008) serta Nugraha et al. (2015). Kajian yang dilakukan oleh Hendratno dan Amypalupy (2008) serta Nugraha et al. (2015) dilakukan pada kondisi harga yang berbeda. Berdasarkan kajian oleh Hendratno dan Amypalupy (2008) serta Nugraha et al. (2015) diketahui bahwa dengan menurunnya harga karet saat ini, terjadi penambahan persentase matang sadap kebun masing-masing sebesar $75 \%$ pada klon PB 260, PR 261, dan RRIC 100 untuk mencapai titik impas (Break Even Point). Perbandingan hasil kajian tersebut ditampilkan padaTabel 2.

Tabel 2. Penentuan formula buka sadap pada beberapa jenis klon dan tingkat harga

\begin{tabular}{|c|c|c|c|c|c|c|c|}
\hline \multirow{2}{*}{ KarakterKlon } & \multirow{2}{*}{ JenisKlon } & \multicolumn{2}{|c|}{$2008(\mathrm{US} \$ 2,4)^{*}$} & \multicolumn{2}{|c|}{2015 (US\$ 1,64)** } & \multicolumn{2}{|c|}{ Feb $2016(\text { US\$ } 1,06)^{* * *}$} \\
\hline & & (Pohon/ha) & $(\% / \mathrm{ha})$ & (Pohon/ha) & $(\% / \mathrm{ha})$ & (Pohon/ha) & $(\% / \mathrm{ha})$ \\
\hline \multirow{2}{*}{ Quick Starter } & PB 260 & 120 & 17 & 210 & 38 & 288 & 52 \\
\hline & IRR 118 & - & - & 306 & 55 & 420 & 76 \\
\hline \multirow[t]{2}{*}{ Moderate } & PR 261 & 202 & 22 & 354 & 64 & 485 & 87 \\
\hline & BPM 24 & - & - & 414 & 75 & 568 & 102 \\
\hline Slow Starter & RRIC 100 & 282 & 52 & 495 & 89 & 679 & 122 \\
\hline
\end{tabular}

Sumber: *Hendratno dan Amypalupy (2008);**Nugraha et al. (2015); ***data olahan (2016)

Keterangan: kerapatan tanaman 555 pohon/ha

Dari Tabel 2 diketahui bahwa pada saat harga karet US\$2,4 per kg, untuk mencapai break even point, tanaman karet dari berbagai jenis klon (quick starter, moderate, dan slow starter) dapat dibuka sadap lebih awal (kurang dari $60 \%$ ) dibandingkan dengan formula buka sadap konvensional. Sedangkan pada saat harga karet US\$ 1,64 per $\mathrm{kg}$, untuk mencapai break even point, hanya klon quick starter (PB260 dan IRR 115) yang dapat disadap lebih awal (kurang dari 60\%) sedangkan untuk klon moderate dan slow starter baru dapat mencapai break even point jika dibuka sadap pada saat persentase matang sadap kebun mencapai lebih dari $60 \%$. Selanjutnya pada Tabel 2 juga ditampilkan hasil perhitungan pada saat harga US\$ 1,06 diperoleh bahwa untuk mencapai break even point, hanya klon PB 260 yang dapat dibuka sadap lebih awal (kurang dari 60\%) sedangkan klon-klon lain membutuhkan persentase matang sadap lebih dari $60 \%$ untuk mencapai break even point. Bahkan, klon BPM 24 dan RRIC 100 belum bisa mencapai break even point pada kondisi harga US\$ 1,06 per $\mathrm{kg}$ meskipun seluruh tanaman telah matang sadap.

Hal ini menunjukkan dengan berubahnya harga karet dan kenaikan biaya produksi per tahun, terdapat perlambatan buka sadap pada klon moderate dan slow starter dibandingkan dengan klon quick starter. Analisa perlambatan buka sadap pada klon moderate dan slow starter dibandingkan dengan klon quick starter ditampilkan pada Tabel 3. 
Tabel 3. Analisis perlambatan buka sadap pada klon moderate dan slow starter dibandingkan klon quick starter

\begin{tabular}{lcccc}
\hline $\begin{array}{c}\text { Karakter } \\
\text { Klon }\end{array}$ & Jenis Klon & $\begin{array}{c}\text { Persentase matang } \\
\text { sadap (\%) }\end{array}$ & $\begin{array}{c}\text { Buka sadap } \\
\text { (bulan) }\end{array}$ & $\begin{array}{c}\text { Perlambatan buka sadap } \\
\text { (bulan) }\end{array}$ \\
\hline Quick & PB 260 & 38 & 48 & 0 \\
Moderate & PR 261 & 64 & 56 & 8 \\
Slow & RRIC 100 & 89 & 64 & 16 \\
\hline Keterangan & : Dasar perhitungan adalah persentase buka sadap pada klon PB 260 (Nugraha et al., 2015) \\
& Peningkatan persentase buka sadap setiap 6 bulan adalah 20\% (Suprapto, 2015)
\end{tabular}

Dari Tabel 3 diketahui bahwa untuk mencapai break even point pada saat harga US\$ 1,64, tanaman moderate dan slow starter mengalami perlambatan buka sadap dibandingkan formula konvensional (60\% dengan lilit batang $45 \mathrm{~cm}$ ). Dibandingkan dengan klon PB 260 yang dapat mencapaibreak event point jika dibuka sadap pada saat persentase matang sadap kebun mencapai $38 \%$, dibutuhkan tambahan waktu 8 bulan dan 16 bulan masing-masing pada klon PR 261 dan RRIC 100 untuk mencapai break even point. Berdasarkan hal tersebut, penanaman klon dengan produktivitas awal yang tinggi merupakan kunci bagi suatu perkebunan agar mencapai break even point lebih cepat, terutama pada saat harga karet rendah.

\section{Kesimpulan}

Penundaan buka sadap hingga lilit batang mencapai $50 \mathrm{~cm}$ akan ekonomis dengan pemilihan klon yang memiliki produktivitas awal yang tinggi. Penundaan buka sadap dari lilit batang $45 \mathrm{~cm}$ menjadi $50 \mathrm{~cm}$ memerlukan waktu 6-12 bulan tergantung kerapatan tanaman dan jenis klon. Penanaman klon dengan produktivitas awal yang tinggi merupakan kunci bagi suatu perkebunan agar mencapai break even point lebih cepat, terutama pada saat harga karet rendah. Kriteria matang sadap kebun yang berbeda sesuai jenis klon dan perubahan harga masih menguntungkan secara ekonomis. Perlu kajian yang lebih luas mengenai penundaan buka sadap terhadap klon-klon anjuran baru.

\section{Daftar Pustaka}

BadanPusatStatistik. (2013). Statistik karet Indonesia 2013. Jakarta : BadanPusatStatistik.

DirektoratJenderal Perkebunan. (2014). Statistik perkebunan: Karet. Jakarta : DirektoratJenderal Perkebunan.

Hendratno, S dan Amypalupy, K. (2008). Formula buka sadap kebun karet pada kondisi perekonomian yang dinamis. Jurnal Penelitian Karet, 26(1), 65-75.

International Tripartite Rubber Council. (2015). Progress Report on Cost of Production. Bahan pada Joint Meeting between Intenational Tripartite Rubber Council (ITRC) and The Board of Directors (BODs) of International Rubber Consortium Limited (IRCo). Jakarta, Indonesia.

Karyudi dan Junaidi. (2009). Penggunaan stimulan untuk meningkatkan produktivitas tanaman karet. Pertemuan Teknis Eksploitasi Tanaman Karet 2009, Medan, Desember 2009.

Kuswanhadi dan Herlinawati, E. (2012). Penyadapan. Saptabina Usahatani Karet Rakyat (pp.93-101). Edisi khusus cetakan keenam. Sembawa : Balai Penelitian Sembawa-Pusat Penelitian Karet. 
Lukman. (1979). Pembukaan sadapan dan stimulasi sehubungan dengan besarnya lilit batang. Bulletin Balai Penelitian Perkebunan Medan, 10(3), 113-114.

Lukman. (1980). Penundaan pembukaan sadapan dari lilit batang $45 \mathrm{~cm}$ menjadi $50 \mathrm{~cm}$ pada klon GT 1. Bulletin Balai Penelitian Perkebunan Medan, 10(3),115125.

Nugraha, I.S., Alamsyah, A., Ismawanto, S., dan Cahyo, A.N. (2015). Defining the formulation of tapping opening under the current economic conditions. Proceedings $I R R D B$ International Rubber Conference 2015, Ho Chi Minh, November 2015.

Obouayeba, S., Boa, D.,Ake, S., andLacrotte, R. (2002). Influence of age and girth at opening on growth and productivity of Hevea. Indian Journal of Natural Rubber Research, 15(1), 66-71.

Samuel, O, Eric, S.F., Modeste, K.K., Fanlegue, C.L., Okoma,K.M., N'guessan, A.E.B., Christophe, K, dan Severin, A. (2012). Influence of girth and age at opening on rubber yield, biochemical and tapping paneldryness parameters of Hevea brasiliensis in determining tapping norms. International Journal of Biosciences, 2,10(1), 1-18.
Singapore Commodity Exchange. (2015). Historical data: daily rubber price. Singapore : Singapore Commodity Exchange.

Sivakumaran, S. (2013). Short-medium and long-term solutions for problem of tapper shortage and ising cost of production. International Workshop on Latex Harvesting Technology, Binh Duong, November 2013.

Suprapto. (2015). Komunikasi personal: data waktu yang dibutuhkan untuk penambahan persentase matang sadap pohon. Tidak dipublikasi. 